\title{
POLÍTICAS PÚBLICAS DE PARTICIPACIÓN CIUDADANA. EL PRESUPUESTO PARTICIPATIVO Y LA PRODUCCIÓN DE CIUDAD.
}

\author{
Eje 4: Hábitat e infraestructura
}

\author{
Pantaleon María Julia
}

Laboratorio de Tecnología y Gestión Habitacional - FAU - UNLP, Argentina, juliapantaleon@gmail.com

\section{RESUMEN}

El presente trabajo expone los avances en el estudio del instrumento de gestión territorial denominado presupuesto participativo y su relación con el proceso de producción de la ciudad.

El concepto de producción de la ciudad es entendido según lo plantea Pirez (1994) por la acción, relación y negociación de diferentes actores movilizados por diferentes intereses y lógicas (económicas, políticas, necesidad, conocimiento). En este contexto, la implementación de un instrumento como el presupuesto participativo por parte de un gobierno local, implica cierto interés de este por incorporar a la sociedad en el proceso de producción de la ciudad desde otro rol, complementando sus lógicas de acción.

El presupuesto participativo es un proceso a través del cual la población de un territorio define el destino de una parte de los recursos públicos, permitiendo así conocer sus demandas y prioridades de inversión. Entre los fines que persigue este instrumento se enuncian: acercar el Estado a la sociedad, promover una distribución equilibrada de los recursos en el territorio, lograr un uso eficiente de los mismos, y hacer más transparentes y democráticos los procesos de la administración pública.

El caso particular de estudio es el de la ciudad de La Plata en los años 2008 y 2015 . Aquí el presupuesto participativo fue implementado por una administración que pretendía generar un nuevo modo de gestionar la ciudad, acercar el Estado a la sociedad y reconocer a las periferias, entendiéndolas producto del crecimiento de la ciudad, donde no llegaba la inversión pública. En este sentido, analizar los proyectos emergentes de este instrumento permitirá conocer las demandas y prioridades de inversión de la población, que con su decisión incidirán en el proceso de producción de la ciudad. A través de la conformación de una matriz de análisis de las propuestas emergentes del presupuesto participativo y de su georreferenciacion, se pretende identificar: la cobertura de la herramienta en el territorio, las demandas y prioridades de inversión de la población de los diferentes barrios participantes, la respuesta del municipio en relación a estas demandas. El interés de indagar sobre los proyectos emergentes del PP, se fundamenta en que los mismos contienen información que permite entender, comprender y evaluar los resultados de las experiencias de ésta política pública, siendo el fin más tangible del proceso.

\section{PALABRAS CLAVES: PRESUPUESTO PARTICIPATIVO - PRODUCCIÓN DE CIUDAD - POLÍTICAS PÚBLICAS - PROYECTOS}




\section{INTRODUCCIÓN}

Las políticas públicas son entendidas en este trabajo, como un conjunto de iniciativas y respuestas, manifiestas o implícitas, que observadas en un momento histórico y en un contexto determinado permiten inferir la posición del Estado frente a una cuestión que atañe a sectores significativos de la sociedad" (Oszlak, O.; O’Donnell, G., 1976). Esta definición da a entender el carácter relacional de las políticas públicas y la diversidad de actores e intereses constantemente en tensión que coexisten en ellas. El análisis de las mismas intenta facilitar la comprensión de la relación entre Estado y sociedad. Complementando esta postura, (Díaz, 1998) explica a las políticas públicas como un "proceso social complejo, a lo largo del cual es posible ver desagregados en su accionar a los sectores de los aparatos estatales y también a los sectores de la sociedad, que bajo formas institucionalizadas (o no) y en torno a una cuestión, configuran campos de relaciones sociales (relaciones de poder, que implican relaciones de fuerza de producción instrumental y simbólica) al adoptar sucesivas tomas de posición y actuar en consecuencia, transformando la realidad". Aquí es relevante destacar la caracterización que se realiza de la política pública como un proceso social complejo, que no transcurre en forma lineal y que además en el mismo se, entrecruzan diferentes posiciones de actores que se fundamentan en valores y racionalidades distintas.

Los actores, según explica Robirosa (2008), son individuos, grupos, organizaciones o instituciones que se caracterizan o identifican a partir de un papel, rol o posición particular que asumen en un escenario social, según sus propósitos o intereses respecto del escenario o lo que se procesa en él. Por su lado, Arocena (1995) define como actor local a todos aquellos agentes que, en el campo político, económico, social y cultural, son portadores de propuestas que tiendan a capitalizar mejor las potencialidades locales. Ambos autores, coinciden en que, dentro de los distintos momentos de una política pública, intervienen diferentes actores: la población afectada, los funcionaros, los asesores, entre otros. De esta manera queda evidenciado que las políticas públicas no pueden ser contempladas sólo decisiones del Estado, sino que deben estar también las de la ciudadanía involucrada en el proceso.

En este punto es relevante introducir al tema de la participación en las políticas públicas, el cual ha tomado diferentes denominaciones según a que quiera uno referirse: política, social, ciudadana, popular, comunitaria, etc. Para este trabajo se tomó la clasificación presentada por Cunill Grau (1991) para explicar las diferencias entre los términos enunciados. La participación ciudadana, según la autora mencionada, implica la interacción expresa entre el Estado y la sociedad civil, donde estos últimos se adentran en la dinámica del primero. A diferencia de esto, la participación social refiere al agrupamiento de individuos para la defensa de intereses sociales, pero donde la relación se da con organizaciones sociales que no se vinculan con el Estado. El caso de la participación comunitaria y su relación con lo estatal se diferencia por tener un carácter de asistencia de los organismos para obtener recursos destinados a satisfacer necesidades de la vida cotidiana del grupo social interesado. La participación popular hace referencia a experiencia de carácter asociativo (cooperativas, autogestión) y tiene su foco en la transformación de la dominación de clase "implica un intento de redistribución del control tanto de los recursos como del poder a favor de aquello que viven de su propio trabajo" (Pagani M. L., 2015). La participación esta en el trabajador y no en el ciudadano. Por otra parte, la participación política, se desarrolla a través de órganos de intermediación como son los partidos políticos. Aquí se tomará la definición de participación ciudadana, ya que es la que refiere a una interacción entre sociedad y Estado, donde los actores de aquella intentan formar parte del proceso de toma de 
decisiones con el fin de conseguir un beneficio de la política implementada. En este marco es que se desarrollan los presupuestos participativos generalmente.

La participación ciudadana en Argentina tiene sus orígenes a mitad de siglo XX con los avances y la modernización de la sociedad y del Estado argentino, con una progresiva implementación a través de los años. Un estudio de este tema lo realizan Rofman y Foglia (2015) tomando el período desde los años '90 a la actualidad, momento donde se institucionaliza la participación ciudadana. Dentro del período propuesto por las autoras, se hace referencia a tres momentos de la relación Estado - sociedad, caracterizados como: asistencia, movilización, institucionalización. La primera etapa, durante el Estado neoliberal de la década del '90, donde la participación se concentró en las políticas sociales de corte asistencial. La segunda etapa es la vinculada con la emergencia de la crisis económica y social de los años 2000 donde la participación asumió la forma de protesta y movilización. El tercer momento al que Rofman y Foglia aluden, es el que emergió paralelamente al proceso de revalorización del papel del Estado, en donde se evidencia una institucionalización de la participación y, donde la misma fue asumiendo otros carriles más vinculados a políticas con enfoque de derechos. Este proceso encuentra una expresión significativa en los niveles locales de gobierno donde se observa una diversidad de mecanismos participativos, en el marco de procesos interjuridiccionales de procesamiento de las políticas (Rofman, A.; Foglia, C, 2015).

Haciendo una comparativa con la trayectoria de los presupuestos participativos, puede decirse que, en relación a las etapas mencionadas, el origen de los mismos se da en la primera, pero toman mayor relevancia, expansión y definición en la segunda y tercera, con un rol diferente de la sociedad y el Estado municipal.

Los presupuestos participativos según Rofman y Foglia se encuentran dentro de las políticas de participación ciudadana. Estas hacen referencia a espacios de articulación cuyo principal objeto es promover el protagonismo directo de la ciudadanía en las políticas públicas (Rofman, A.; Foglia, C, 2015). Son políticas abiertas, para un espectro muy grande de actores diversos. Las autoras explican que este tipo de políticas son diseñadas y llevadas a cabo por el nivel municipal generalmente sin injerencia de otros niveles estatales. Resaltan también que los presupuestos participativos han sido una vía para fortalecer la legitimidad política de los gobiernos locales y la participación de la ciudadanía. Si bien es unos mecanismos interesantes para la toma de decisiones, sus impactos en la democratización de la vida política o la reducción de las desigualdades es una cuestión que queda abierta dado el escaso porcentaje de presupuesto implicado. Esto último se vincula directamente con el proceso de producción de la ciudad, entendido este como el conjunto de interacciones de diferentes actores que se mueven respondiendo a diferentes lógicas (Pirez, 1995). En este sentido la definición de participación ciudadana en la planificación y gestión del territorio, aportada por Reese (2003) es adecuada ya que hace referencia a los procesos organizados y sistemáticos mediante los cuales se garantiza a la comunidad la posibilidad de emitir opiniones, sugerencias o propuestas en forma individual y colectiva y a la obligatoriedad de los organismos municipales involucrados de responder a las inquietudes planteadas. La decisión de una administración pública de implementar el presupuesto participativo en su territorio, habilita en cierta forma a los actores sociales (lógica de la necesidad) a producir ciudad desde otro modo, manifestando sus demandas y decidiendo la prioridad de inversión de una parte de los recursos públicos. 


\section{DESARROLLO}

Como se mencionó anteriormente, el presupuesto participativo, forma parte de las políticas públicas de participación ciudadana que promueven el protagonismo de la ciudadanía en la toma de decisiones públicas, sobre todo en la decisión sobre la adjudicación de recursos. Es uno, dentro de los instrumentos de participación ciudadana, basada en la participación directa de la población en las diversas fases que componen la elaboración y la ejecución del presupuesto público municipal, especialmente en la indicación de las prioridades para la adjudicación de los recursos de inversiones (Reese, 2003).

La ciudad de La Plata ha implementado el presupuesto participativo en diferentes momentos y por diferentes gestiones municipales. Este trabajo abordará los años 2008 y 2015, por ser el comienzo y final de una misma gestión que promovió el presupuesto participativo como un instrumento de innovación en la gestión y lo institucionalizó a partir de un decreto municipal.

\subsection{Presupuesto participativo en La Plata 2008 - 2015: ingreso en la agenda pública}

En el año 2007 triunfa en las elecciones Pablo Bruera quien pertenecía al mismo bloque político que el ex intendente Julio Alak pero que en 2003 conforma el Frente Renovador Platense. A partir de ese momento, Bruera comienza una campaña política a partir de caminatas por los barrios y de la línea telefónica "Bruera te escucha" para atender reclamos que intentaba resolver desde el Concejo Deliberante. Ya como intendente de ciudad, Bruera propone, según lo expresa Pagani (2015), una serie de políticas "novedosas", de alta visibilidad e impacto en la ciudad, entre las que se destacó el presupuesto participativo y también el reciclado de residuos secos, la recuperación del espacio público con el mejoramiento de plazas y ciertas deudas de la gestión anterior como pavimentación, tránsito y cambios en el sistema de transporte.

En esta nueva gestión el presupuesto participativo se posiciona como el eje central para superar la crisis de representación y como nuevo modo de de gestionar la ciudad contemplando tanto al casco como a la periferia. Su creación fue a través del Decreto $N^{\circ} 254 / 08$ y se reglamentó su funcionamiento por el Decreto $\mathrm{N}^{\circ} 343 / 08$. Aquí se expresaba la organización territorial del presupuesto participativo en 31 regiones de la periferia, tomando como referencia las Delegaciones creadas a través de la Ordenanza 7888/92.

La coordinación del presupuesto participativo 2008 estuvo a cargo de la Dirección de Presupuesto Participativo (DPP) que inicialmente dependía de la Jefatura de Gabinete. Esta Dirección tenía como función la organización de las asambleas y el sistema de votación; capacitar a los coordinadores, facilitadores y redactores de actas y secretario de asistencia de asambleas, sistematizar las propuestas generadas por los vecinos y realizar el seguimiento de los proyectos ganadores.

A partir de la segunda edición del presupuesto participativo (año 2009) se produce un cambio. El decreto $\mathrm{N}^{\circ} 343 / 08$ que reglamentaba este instrumento se deja de implementar debido que la organización de las asambleas pasa a manejarse desde un sector del socialismo platense. Es entonces cuando el presupuesto participativo comienza a llevarse a cabo por dos áreas: el Consejo de Presupuesto Participativo (CPP), con la responsabilidad de organizar el ciclo de asambleas, el estudio de viabilidad de los proyectos y la consulta popular; y la Dirección Ejecutiva del Presupuesto Participativo (DEPP), encargada de ejecutar los proyectos elegidos. Ambas áreas dependían directamente de la Intendencia. Esta división en la estructura organizativa del 
presupuesto participativo pudo generar conflictos en relación al modo en que la intersectorialidad es incorporada en la ejecución del instrumento, ya que generar una nueva dependencia puede favorecer la desarticulación y perder la integralidad de los problemas, además de incorporar nuevos actores e instituciones quizás innecesarias. Repetto (2008) menciona que el exceso de subdividir organismos en diferentes áreas puede conllevar a generar tensiones en las relaciones de poder de quienes están a cargo, provocando la ineficacia e ineficiencia del sistema. Estas cuestiones pueden reflejarse en la opinión de algunos vecinos en relación a lo producido con los recursos de esta herramienta.

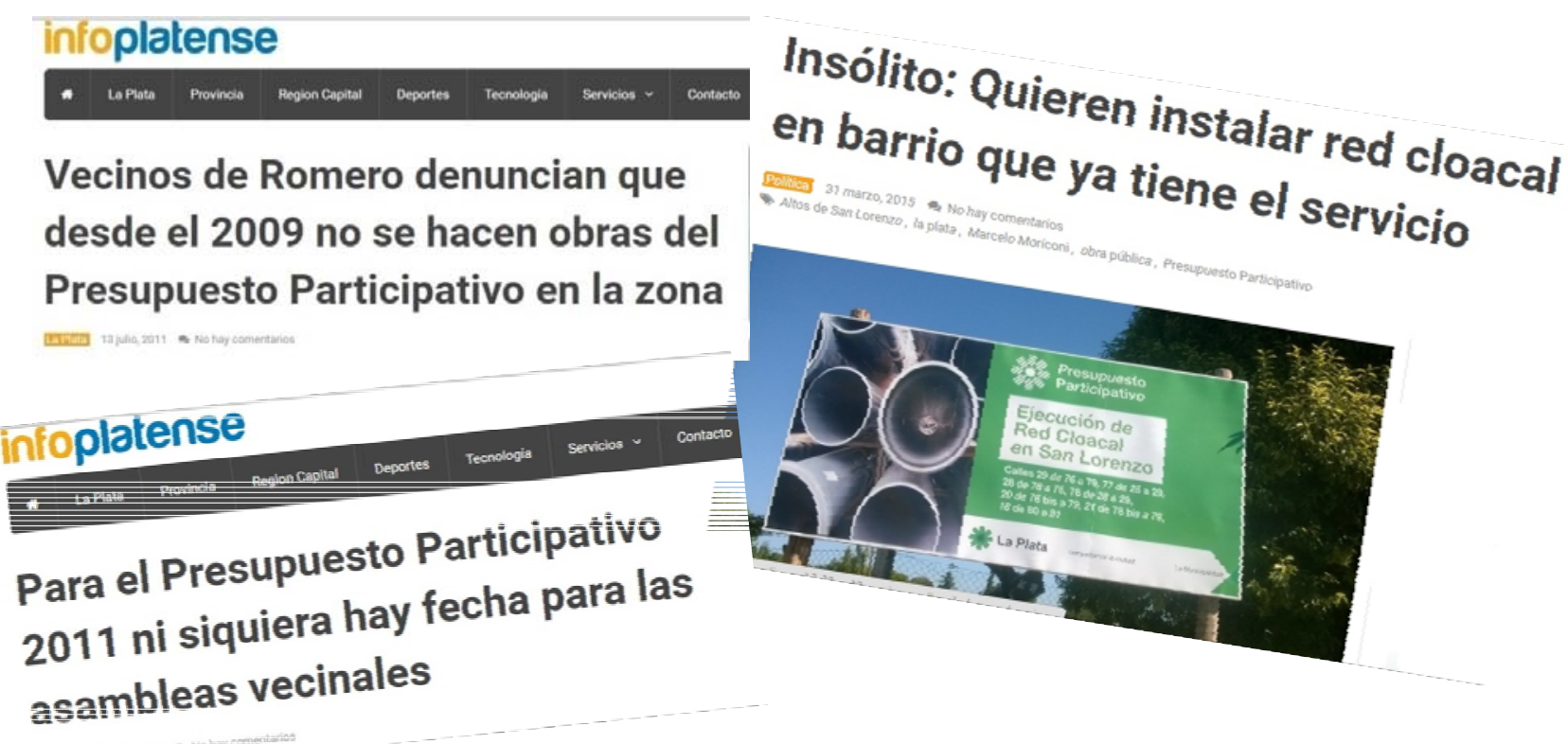

Fig. 1: Información periodística. Fuente: Internet http://infoplatense.com.ar/.

En relación a su desarrollo en el tiempo el presupuesto participativo en la ciudad de La Plata, se implementó ininterrumpidamente desde el año 2008 hasta el 2013, cuando la ciudad se vio afectada por una inundación de carácter extraordinario, año en que se retrasaron las fechas para las actividades de este instrumento. Durante 2014 y 2015 se llevó a cabo el presupuesto participativo por la misma gestión municipal. En el año 2016, a partir las elecciones electorales, se produce un cambio en las autoridades municipales que deciden durante el primer año de gestión no abordar el tema del presupuesto participativo. En el año 2017 lo ponen en marcha en un formato de plataforma web. Actualmente se están ejecutando las obras del mismo, pero no se convocó a una nueva edición 2018 de presupuesto participativo.

\subsection{Presupuesto participativo La Plata 2008 y 2015: organización territorial y, prioridades de inversión}

En relación a la organización del presupuesto participativo en el territorio de La Plata, se observa que desde su primera implementación en 2008 ha experimentado cambios, producto según lo expresan algunos funcionarios de la dinámica de revisión y ajuste propia de la herramienta.

En el primer año de implementación se organizó el territorio en 31 regiones de la periferia, tomando como referencia las Delegaciones creadas a través de la Ordenanza 7888/92. Para garantizar una máxima participación de los ciudadanos, y teniendo en cuenta que algunas Delegaciones superan los 40.000 habitantes, se estableció subdividir en 3 asambleas a aquellas 
que superen ese número, en 2 a las de más de 15.000 habitantes y las regiones de menos de 15.000 habitantes no se subdividirán.

Para el año 2015 se llega a una organización en 30 regiones presupuestarias en total: las regiones del casco se unifican en Casco 1 y Casco 2, y desaparecen las correspondientes a Los Hornos III, San Carlos III, Altos de San Lorenzo III, Tolosa III y Villa Elvira III, sin especificarse en ningún documento si fueron absorbidas por otras regiones presupuestarias. Por otro lado, se crea la delegación Arana en parte de lo que fue la Subdelegación Villa Elvira III.

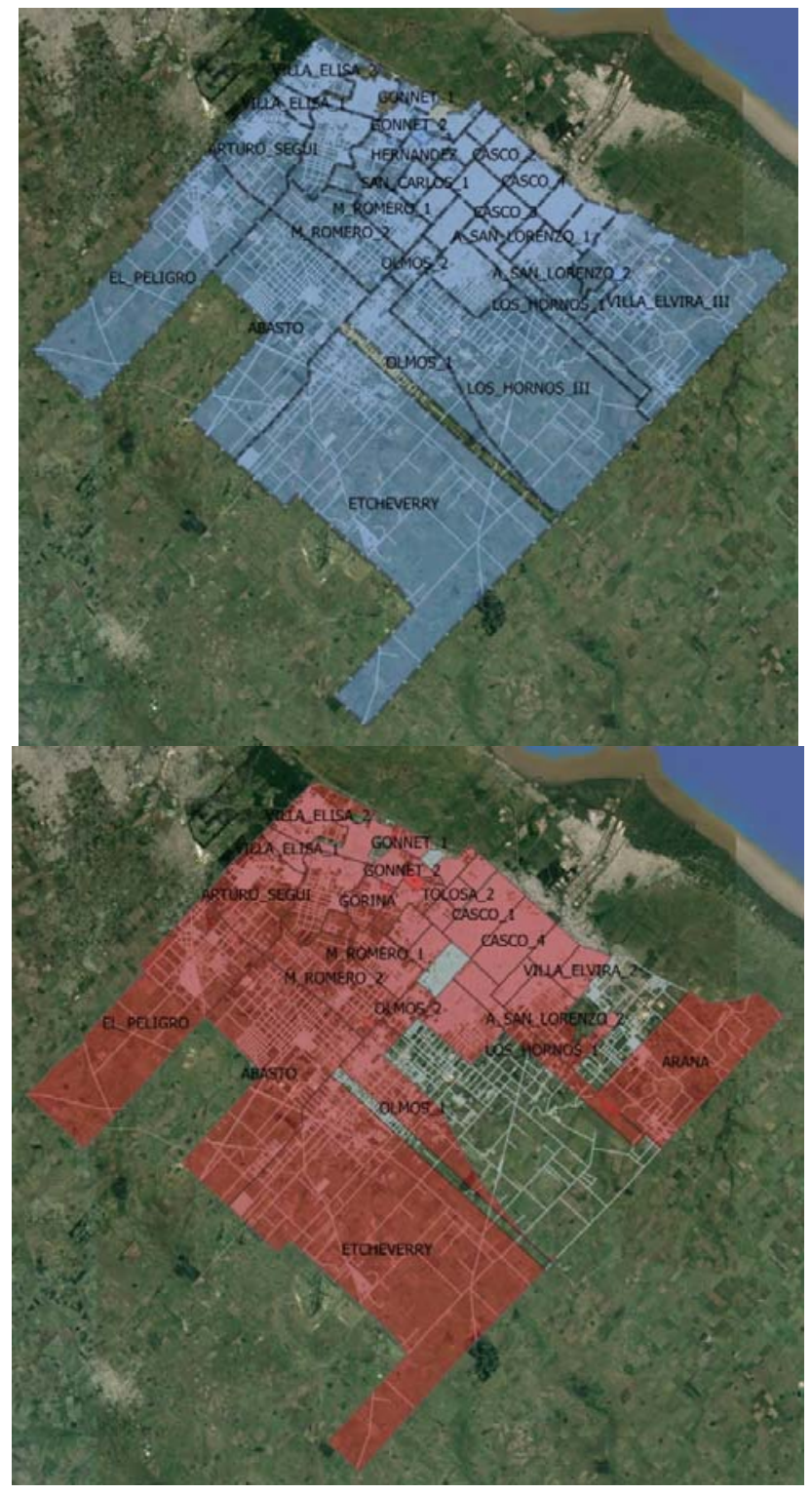

Fig.2: Organización territorial del PP año 2008 y 2015 en La Plata. Imagen satelital de Google Earth + Elaboración propia de mapeo en GIS de la zonificación.

Durante todo el período los recursos implicados en el presupuesto participativo, que significan un porcentaje del presupuesto global del municipio, se fueron incrementando año a año. Sin embargo, los mismos llegaron a representar tan solo el $6 \%$ del presupuesto global del municipio. 
En diversos estudios académicos se expresa que para que las obras sean de mayor impacto territorial el presupuesto participativo debería representar por lo menos el $15 \%$ del presupuesto global, o ser articulado con otros instrumentos o políticas públicas para poder abordar diferentes demandas (Cabannes 204 y 2007).

A continuación, se expresa una síntesis de los números implicados en el presupuesto participativo durante el período 2008 -2015 que pertenecen a un informe realizado por quien fue el Secretario del Consejo del Presupuesto Participativo. Aquí se muestra el incremento presupuestario del presupuesto participativo entre el comienzo y finalización de esta gestión, una merma en la cantidad de proyectos presentados y priorizados, así como también la tendencia hacia los proyectos de Infraestructura Urbana por sobre los de Acción Comunitaria. Esto último es una catalogación desde las áreas municipales que llevaban adelante el presupuesto participativo donde: "Llamamos "Infraestructura Urbana" a las obras hidráulicas, asfalto y mejorado de calles, redes de agua y cloacas, construcción de puentes, veredas y bici sendas, instalación de luminarias y semáforos, eliminación de barreras arquitectónicas etc. Llamamos "Acción Comunitaria" a la ampliación, refacción, equipamiento y/o construcción de centros de salud, escuelas municipales, centros culturales, espacios verdes, talleres de artes y oficios, etc" Sortino, (2015).

EL PRESUPUESTO PARTICIPATIVO EN NÚMEROS

\begin{tabular}{|c|c|c|c|c|c|c|c|c|}
\hline INDICADORES & 2008 & 2009 & 2010 & 2011 & 2012 & 2013 & 2014 & 2015 \\
\hline Presupuesto asignado ${ }^{i}$ & 7 & 14 & 20 & 40 & 100 & 120 & 125 & 150 \\
\hline Proyectos presentados & 513 & 341 & 368 & 255 & 275 & 142 & 131 & 150 \\
\hline Proyectos elegidos & 39 & 40 & 43 & 40 & 40 & 40 & 30 & 30 \\
\hline Proyectos Infraestructura Urbana & $64,9 \%$ & $48,5 \%$ & $61,2 \%$ & $77,5 \%$ & $83,5 \%$ & $87,5 \%$ & $97 \%$ & $94 \%$ \\
\hline Proyectos Acción Comunitaria & $35,1 \%$ & $51,5 \%$ & $38,8 \%$ & $22,5 \%$ & $16,5 \%$ & $12,5 \%$ & $3 \%$ & $4 \%$ \\
\hline Asistencia a asambleas & 3.342 & 3.200 & 5.230 & 2.682 & 3.570 & 2.150 & 2.528 & 6.000 \\
\hline Asistencia a Consulta Popular iii & 17.686 & 29.574 & 45.037 & 49.561 & 51.104 & 52.017 & 32.198 & 34.000 \\
\hline Participación s/ población iv & $3,8 \%$ & $6,3 \%$ & $9,6 \%$ & $9,9 \%$ & $10,2 \%$ & $10,4 \%$ & $6,5 \%$ & $8 \%$ \\
\hline Hogares favorecidos ${ }^{1 \mathrm{v}}$ & 2.100 & 6.800 & 8.695 & 9.053 & 37.680 & 53.860 & 29.920 & 30.512 \\
\hline Satisfacción s/ total de hogares vi & $1 \%$ & $3,1 \%$ & $3,9 \%$ & $4 \%$ & $16,3 \%$ & $22,8 \%$ & $13,5 \%$ & $15 \%$ \\
\hline
\end{tabular}

Fig.3: El presupuesto participativo en números según el Secretario del CPP de la Municipalidad de La Plata. Los valores de Presupuesto asignado son en millones de pesos argentinos. Fuente: http://mensajera.net/wpcontent/uploads/2015/08/Presupuesto-participativo.pdf

En relación a las demandas presentadas y las prioridades finalmente seleccionadas para su ejecución, analizando lo presentado por el Ex Secretario del CPP, se observa:

Por un lado, una disminución en la cantidad de los proyectos presentados, que según el cuadro de la Fig. 4 no se debería a una disminución de participantes en el proceso del presupuesto 
participativo. Una de las hipótesis es que se conformaron proyectos más ambiciosos, que pretendían contener más acciones dentro de un mismo proyecto.

Por otro lado, la cantidad de proyectos priorizados que fue variando dependiendo de la cantidad de regiones presupuestarias conformadas en cada edición del presupuesto participativo en la ciudad. En este punto aparecen ciertas inconsistencias en relación a la cantidad de regiones presupuestarias de algunos años y los proyectos elegidos si correspondiese un proyecto por región presupuestaria.

\begin{tabular}{|c|c|c|c|c|c|c|}
\hline AÑO & $\begin{array}{c}\text { MONTO } \\
\text { PP(\$ARG) }\end{array}$ & $\begin{array}{c}\text { MONTO GLOBAL } \\
\text { MUNICIPIO }\end{array}$ & \%de PP en PG & CANTIDAD DE ZONAS & $\begin{array}{c}\text { CANTIDAD DE PROYECTOS } \\
\text { PRESENTADOS }\end{array}$ & $\begin{array}{c}\text { CANTIDAD DE PROYECTOS } \\
\text { ELEGIDOS }\end{array}$ \\
\hline 2008 & 7.000 .000 & 334.464 .132 & 2 & 35 & 513 & 39 \\
\hline 2009 & 14.000 .000 & 428.010 .993 & 3 & 40 & 341 & $40 / 126$ \\
\hline 2010 & 20.000 .000 & 560.808 .524 & 4 & 40 & 368 & $43 / 45$ \\
\hline 2011 & 40.000 .000 & 711.804 .860 & 6 & 39 & 255 & 40 \\
\hline 2012 & 100.000 .000 & 1.142 .538 .935 & 9 & 39 & 275 & 40 \\
\hline 2013 & 120.000 .000 & no publicado & & 39 & 142 & 40 \\
\hline 2014 & 125.000 .000 & 1.677 .383 .900 & 7 & 39 & 131 & 30 \\
\hline 2015 & 150.000 .000 & 2.463 .447 .276 & 6 & 30 & 150 & 30 \\
\hline
\end{tabular}

Tabla 1: Incidencia del presupuesto participativo en el Presupuesto Global del Municipio de La Plata. Años 2008 y 2015.

Fuente: elaboración propia en base a valores de presupuesto de gastos de la administración http://www.concejodeliberante.laplata.gov.ar/ y a Sortino (2015) http://mensajera.net/wpcontent/uploads/2015/08/Presupuesto-participativo.pdf.

En las siguientes imágenes se observa la organización territorial de los años 2008 y 2015 , con los proyectos seleccionados para ser ejecutados.

Cada círculo representa una acción dentro de un proyecto elegido, es decir que cada proyecto está conformado por acciones diversas.

Aquí vuelven a manifestarse las diferencias de los límites de las regiones presupuestarias en los años. Por otro lado, puede apreciarse que la localización de las acciones de los proyectos tiende a focalizarse en algunas áreas de la ciudad, provocando la concentración de recursos. De aquí que surjan inconvenientes entre actores más o menos beneficiados por este instrumento de gestión territorial. Estas cuestiones serán abordadas más adelante en el proceso de investigación a partir de entrevistas a vecinos participantes del proceso. 


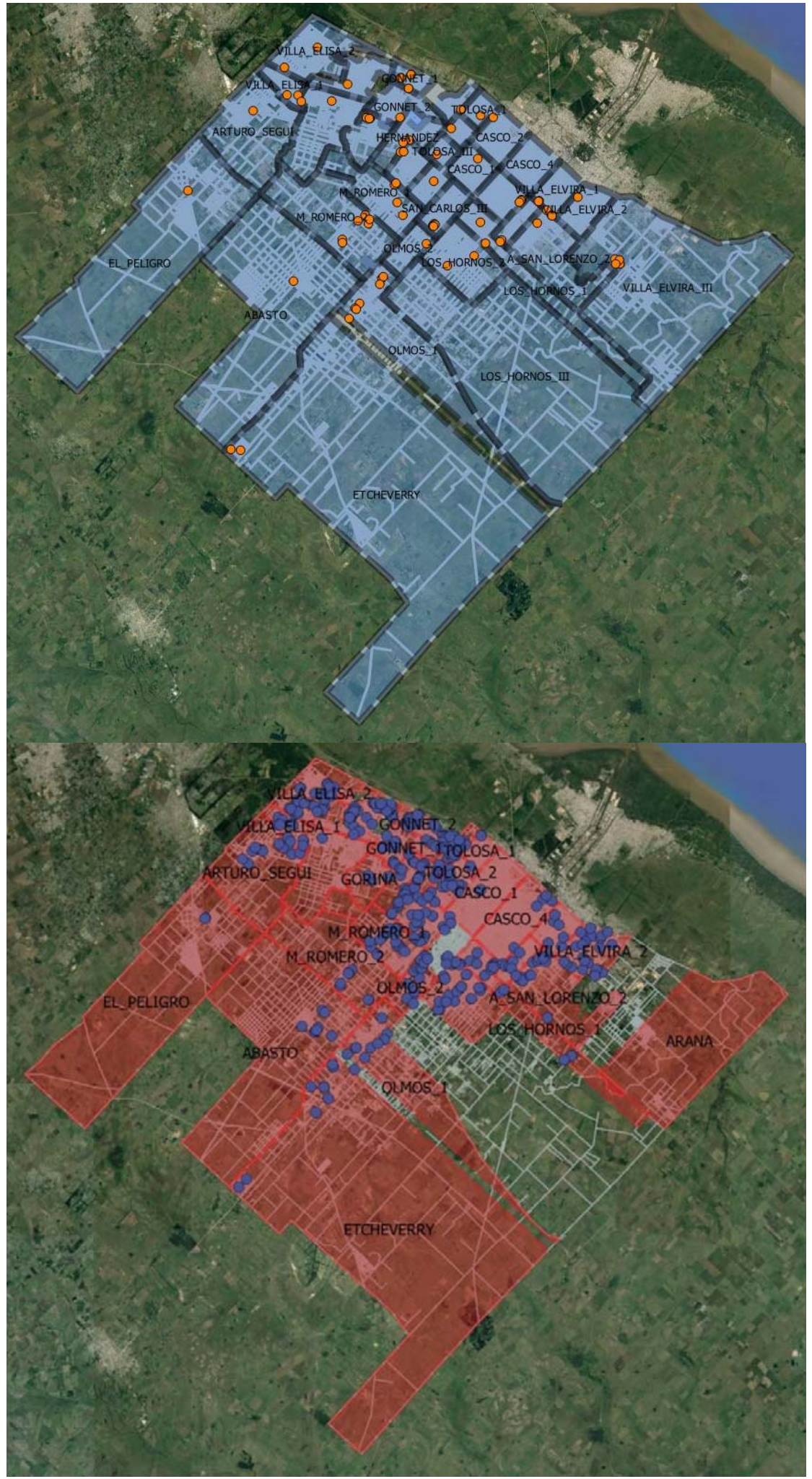

Fig.2: Organización territorial y proyectos priorizados del presupuesto participativo en año 2008 y 2015 - La Plata. Imagen satelital de Google Earth + Elaboración propia de mapeo en GIS. 


\section{CONCLUSIONES}

Los instrumentos de gestión territorial como es el presupuesto participativo permiten generar cambios y transformaciones en las ciudades y territorios que, según sea su modo de implementación, podrán favorecer al abordaje integral de los problemas, con intenciones redistributivas e inclusión de diferentes actores.

En el caso del presupuesto participativo implementado en La Plata, se puede observar que produjo un avance en el modo en que el municipio tomaba las decisiones en temas de construcción de la ciudad, y democratizar los procesos de la administración pública. Sin embargo, fue un instrumento con ciertos inconvenientes a la hora de pasar de la teoría a la acción, por ejemplo:

- La organización territorial del presupuesto participativo fue cambiando a través de las diferentes ediciones del mismo, lo que produjo un constante ajuste y revisión por parte de los vecinos participantes en relación a saber cuál es su área de influencia y la construcción de relaciones sociales con otros vecinos intervinientes. Por otro lado, se identificaron conflictos en relación a la cobertura del presupuesto participativo en el municipio: las asambleas se realizaban en 30/40 zonas mientras que los barrios de la ciudad son muchos más, además en 2015 no se registró publicada una zonificación concreta de las regiones presupuestarias quedando zonas sin cubrir, o proyectos generados para otras zonas;

- En relación a la comunicación sobre las asambleas, lugares y horarios y sobre los proyectos a votar y elegidos, se pudo advertir según fuentes periodísticas locales problemas demoras o inexistencia de información, que atentó contra la transparencia de la herramienta;

- El proceso de ejecución de los proyectos se caracterizó por la falta articulación entre dependencias municipales y de estas con entes prestadores de servicios que originaron demoras e incumplimiento en la ejecución de los proyectos, atentando así con la eficacia y eficiencia del sistema y provocando descreimiento en la población;

- Inexistencia de un organismo que fiscalice al presupuesto participativo desde lo presupuestario, la participación y las obras, otro aspecto que atenta contra la transparencia y la participación;

- Se contemplo al presupuesto participativo en la ciudad de La Plata como un instrumento de actuación de corto plazo sin articulación con políticas de mediano y largo plazo que fomenten su utilización y fortalezcan la herramienta, prefiriendo los proyectos de pequeña escala sin pensar en lo que estos generaban en la gran escala.

Estos son sólo algunas de las causas que dejan entrever que el presupuesto participativo en la ciudad no estaba pensado contemplando el concepto de integralidad expuesto, redistribuciún e inclusión. Tampoco se visualiza el interés por la coordinación intersectorial e intereactoral para poder así materializar eficientemente las propuestas y desarrollar esta capacidad estatal para la mejora y fortalecimiento del municipio. 


\section{BIBLIOGRAFÍA}

Cabannes, Y. (2004). Presupuesto Participativo y finanzas locales. Quito, Ecuador.: Programa de Gestión Urbana - UN/HABITAT. Cuaderno de trabajo Num.n137.

Cabannes, Y. (2007). Instrumentos de Articulación entre Presupuesto Participativo y Ordenamiento Territorial. Una síntesis basada en las experiencias de Ariccia (Italia); Belo Horizonte y Guarulhos (Brasil); Bella Vista (Argentina) y Córdoba (España). Porto Alegre, Brasil.: Coordinación URB-AL Red 9 Presupuesto Participativo y Finanzas Municipales. Municipio de Porto Alegre, Brasil.

Concejo Deliberante de La Plata. (2008). Decreto Municipal №254 "Creación del Presupuesto Participativo en la Municipalidad de La Plata". La Plata.

Concejo Deliberante de La Plata. (2008). Decreto Municipal N³43 "Reglamentaicón Decreto Municipal $N^{\circ} 254 l$ Creación del Presupuesto Participativo en la Municipalidad de La Plata". La Plata.

Cunnil Grau. N. (1991). Participación ciudadana. Dilemas y perspectivas para la democratización de los Estado latinoamericanos. Caracas: CLAD.

Díaz, C. (1998). UNLP. Recuperado el Junio de 2017, de http://blogs.unlp.edu.ar/introdsocio3/files/2017/10/Cristina-Diaz-El-ciclo-de-las-politicas-publicaslocales.pdf

Oszlak, O.; O’Donnell, G. (1976). Estado uy políticas estatales en América Latina: Hacia una estrategia de investigación. Buenos Aires: CEDES / G.E. CLASCO .

Pagani, M. L. (2015). "Vos proponés, vos decidís" : Presupuestos participativos y participaciones ciudadanas en La Plata y Morón (2006-2014). La Plata: Presentada en Universidad Nacional de La Plata. Facultad de Humanidades y Ciencias de la Educación para optar al grado de Doctora en Ciencias Sociales. Disponible en: http://www.memoria.fahce.unlp.edu.ar/tesis/te.1178/te.1178.pdf.

Pirez, P. (1995). Actores sociales y gestión de la ciudad. CIUDADES 28. Mexico.

Reese, E. (2003). Instrumentos de gestión urbana, fortalecimiento del rol del municipio y desarrollo con equidad. Lima, Peru.: Lincoln Institute.

Repetto, F. (2009.). La gestión de la ciudad: retos y capacidades necesarias para una intervención integral. In M. Alvarez, \& A. (. Catenazzi, Gestión Municipal y Ciudad. Dilemas y oportunidades. (pp. 23-73.). Buenos Aires.: Programa de Mejora de la Gestión Municipal (PMGM) del Ministerio del Interior de la Nación.

Rofman, A.; Foglia, C. (2015). La participación ciudadana local en la historia argentina reciente (de los '90 a la actualidad): Asistencia, movilización, institucionalización. Revista Estado y Políticas Públicas No 5. , 41-61. 